\title{
Şizofreni Hastalığında Umut Kavramı
}

\section{The Concept of Hope in Schizophrenia Disease}

\author{
Özlem ŞAHIN ALTUN ${ }^{\mathrm{a}}$, Zeynep OLÇUN ${ }^{\mathrm{b}}$
}

\begin{abstract}
ÖZ Şizofreni; düşünce, duygu ve davranışlarda önemli bozulmalara yol açan, bireyi derinden yıkıcı psikopatolojik etkileri olan kronik bir hastalıktır. Şizofreni hastaları hastalığın yol açtı̆̆ı fizyolojik sorunlarla beraber, hastalığa yönelik toplumdaki yanlış bilgi ve inanışların doğurduğu önyargı, damgalanma ve dışlanma sorunlarıyla da karşı karşıyadır. Tüm bu sorunlar, şizofreni hastalarının geleceğe yönelik pozitif beklenti hislerini azaltarak, umutsuzluğun hastalar arasında yaygın olarak görülmesine neden olmaktadır. Umut, şizofreni hastalarının hastalıkla mücadele etmelerini sağlayan, tedavinin etkinliğini artıran iyileşmenin en önemli belirleyicilerinden birisi olarak kabul edilmektedir. Şizofreni hastalı̆̆ının tanı, tedavi ve rehabilitasyon aşamalarında en fazla hastaların yanlarında bulunan sağllk profesyoneli hemşirelerdir. Bu nedenle, umudun artırılmasına yönelik girişimlerin hemşireler tarafından iyi bilinmesi gerekmektedir. Bu derlemenin amacı; şizofreni hastalarının umut düzeylerinin belirlenmesi ve artırmaya yönelik girişimlerde bulunulması konusunda hemşirelere yol göstermek ve bu konuda farkındalık oluşturmaktır.
\end{abstract}

Anahtar Kelimeler: Şizofreni, umut, hemşirelik girişimleri

\begin{abstract}
Schizophrenia is a chronic disease that has destructive psychopathological effects causing profound impairments in thoughts, feelings and behaviors in individuals. Along with the physiological problems caused by disease, the patients with schizophrenia also faces prejudice, stigmatization and alienation problems caused by misinformation and beliefs in society regarding the disease. All these problems reduce the positive expectations patients with schizophrenia for the future and cause widespread despair among these patients. Hope is considered to be one of the most important determinants of healing that increases the effectiveness of the treatment, enabling patients with schizophrenia to fight against the disease. Nurses are the most prominent health care professionals, which are close the patients in the diagnosis, treatment, and rehabilitation stages of the schizophrenia disease. Therefore, interventions used for increasing hope should be known by nurses well. The aim of this review is to guide nurses to perform interventions to determine and increase the levels of hope of the patients with schizophrenia as well as raising awareness in this regard.
\end{abstract}

Keywords: Schizophrenia, hope, nursing interventions

\section{Giriş}

Şizofreni düşünüş, duyuş ve davranışlarda önemli bozuklukların görüldüğü süreğenleşen ve hastaların önemli bir kısmında işlev kayıplarına yol açan ağır bir ruhsal hastalıktır. ${ }^{1,2}$ Genellikle genç yetişkinlik ve ergenlik döneminde ortaya çıan bu hastalık, tüm toplumlarda ve sosyal sinıflarda görülmektedir. Hastalığın genel popülasyonda görülme sıklı̆̆ yaklaşı \% 1 'dir. $^{3}$

Şizofreni hem yaygınlığ 1 hem de genç yaşlarda ortaya çıkarak kişinin hayatında yol açtı̆̆ kayıplar açısından önemli bir halk sağlığı problemidir. Dünya Sağlık Örgütü tarafindan 2010 yılında yapılan Global Hastalık Yükü çalışmasında, en fazla yeti yitimine yol açan ruhsal hastalığın şizofreni olduğu bildirilmiştir. ${ }^{2}$

Sosyal ve bilişsel yeti yitimleri, hastalarının günlük yaşam aktiviteleri, üretkenlik, motivasyon, baş etme, iletişim becerileri ve topluma uyum gibi alanlarda sorunlar yaşanmasına yol açmaktadır. ${ }^{1,4}$ Şizofreni hastaları hastalı̆̆ı yol açtığ $\mathrm{bu}$ olumsuzlukların yanı sıra; önyargı, ayrımcılık, damgalanma ve dışlanma gibi toplumsal sorunlarla da mücadele etmek zorunda kalmaktadır. ${ }^{5}$ Şizofreni hastalarının yaşadıkları fiziksel, psikolojik ve sosyal sorunlar, yaşam kalitelerinin ve benlik saygılarının azalmasına neden olarak, umutsuzluğa yol açmaktadır. ${ }^{6-8}$

Umut mental hastalı̆̆ hastalıklarının üstesinden gelmelerine ve hayatın anlamını keşfetmelerine yardım eder. ${ }^{9}$

Geliş Tarihi/Received:20 -02-2017 Kabul Tarihi/Accepted:19- 11- 2017

a Yrd. Doç. Dr. Atatürk Üniversitesi, Hemşirelik Fakültesi, Psikiyatri Hemşireliği Anabilim Dalı, Erzurum, e-mail: oz_.sahin@mynet.com, ORCID ID: 0000-0001-5800-5099

${ }^{\mathrm{b}}$ Araştırma Görevlisi, Atatürk Üniversitesi, Hemşirelik Fakültesi, Psikiyatri Hemşireliği Anabilim Dalı, Erzurum, ORCID ID: 0000-0003-3368-4288

Sorumlu yazar /Correspondence: Zeynep OLÇUN; Atatürk Üniversitesi, Hemşirelik Fakültesi, Psikiyatri Hemşireliği Anabilim Dalı, Erzurum, e-mail: zeynepolcun6@gmail.com 
Özellikle şizofreni hastalarının umutlu olması, başetme becerilerini artırmakta, tedavi ve iyileşme sürecini ise hızlandırmaktadır. ${ }^{6,10}$ Ancak şizofreni hastalarıyla yapılan çalışmalarda, umutsuzluğun en sik karşılaşılan semptomlardan birisi olduğu bildirilmektedir. ${ }^{11}$ $\mathrm{Bu}$ nedenle; tüm sağlık ekibinin ve özellikle hasta bakımında önemli bir rol üstlenen hemşirelerin, umudun artırılmasına yönelik girişimlerde bulunmaları büyük önem taşımaktadır. Hemşirelerin umudu doğru tanımlamaları, hastalıklar karşısındaki işlevini bilmeleri ve artırmaya yönelik girişimlerde bulunmaları hasta memnuniyetini ve bakımın kalitesini yükseltmektedir. ${ }^{12-14} \mathrm{Bu}$ derleme ile şizofreni hastalarının umutlarının güçlendirilmesi konusunda hemşirelere yol gösterici olmak ve umut kavramıyla ilgili farkındalığın artırılması amaçlanmıştır.

\section{Umut}

Umut, yüzyıllardır toplumlar için merak duyulan bir konu olmuştur. $\mathrm{Bu}$ toplumların kültürel özelliklerine göre, geçmişte umut için çeşitli çağrışımlar atfedilmiş̧tir. Örneğin; yunan mitolojisinde Pandora'nın kutusunda bulunan kötülüklerden biri, Yahudi-Hıristiyan geleneğinde ise Tanri'nın bir erdemi ve ruhani bir armağanı olarak görülmüştür. ${ }^{15}$ Umut kavramının kuramsal temeli ise 13.yüzyıla kadar uzanmaktadır. ${ }^{16} \mathrm{Bu}$ yüzyılda din bilimcisi Aquinas, sonraki yüzy1llarda Hume ve Kant gibi düşünürler umudu, insan doğasında var olan temel duygulardan biri olarak ele almıştır. ${ }^{17}$ Günümüzde ise umut, olumlu bir gelecek beklentisi fikriyle özdeşleştirilmektedir, ${ }^{18,19}$

Umutla ilgili en kapsamlı ve kabul gören görüş, umudun iki boyutta ele alınmasıdır. Bu görüşe göre umudun ilk boyutu; "hedefi elde etme veya hedefi elde edebilmek için kendisinde güç hissetme", ikinci boyutu ise "hedefi elde edebilmek için yollar bulabilme becerisi" olarak tanımlanmaktadır. Kişinin hedefe ulaşmak için yeni yollar araması ve bu hedefe ulaşma yeteneğine olan inancı, karşılaştı̆̆ sorunları çözme konusunda onu cesaretlendirerek, yaşama daha olumlu bakmasını sağlamaktadır. ${ }^{16} \mathrm{Bu}$ nedenle umutlu bireyler karşılaştıkları hastalık ve kriz gibi olumsuz durumlar karşısında; yeni tedavi yolları arama, tedaviye uyum gösterme ve etkili baş etme davranışları sergilemektedir. ${ }^{15}$

\section{Şizofreni ve umut}

Ünlü psikiyatrist Karl Menninger 1959'da yaptığı akademi dersinde umudun klinik ortamda dikkate alınması gereken önemli bir kavram olduğunun altını çizmiştir. ${ }^{20} \mathrm{Bu}$ tarihten itibaren sağlık odaklı disiplinlerde umut kavramına olan ilgi artmıştır. ${ }^{21,22}$ Yapılan çalışmalarda umudun fiziksel ve psikiyatrik hastalıklar üzerinde önemli etkileri olduğu ortaya konulmuştur. ${ }^{14}$ Schrank ve ark. ${ }^{23}$ (2008) umudun hastalıklar karşısında depresyon ve anksiyeteyi azaltıcı, iyilik halini ve başetme becerilerini ise artırıc bir özelliğe sahip olduğunu bildirmişlerdir. Umutsuzluk ise hastalıkların iyileşme süresini uzatmakta, vücudun savunma mekanizmalarını bozarak beklenmedik ölümlere dahi yol açabilmektedir. ${ }^{14}$

Umut şizofreni gibi ruhsal hastalıklarda pozitif baş etme becerilerinin kazanılmasını sağlayan ve iyileşme için gerekli hayati bir bileşendir. Bugünkü psikiyatri literatüründe, umudun mental sağlı uygulamaları ve araştırmalarında hayati bir değişken olması üç önemli nedene bağlanmaktadır. Birincisi; hem iyileşme sürecinin tetikleyicisi hem de bu süreci devam ettirici bir faktör olarak umudun, ruhsal bozukluklardan kurtulma kavramının merkezinde yer almasıdır. İkincisi; umudun ruhsal hastalıkların tedavisinde daha hızlı iyileşme kavramının merkezinde yer almasıdır. Üçüncü olarak; hem hastalar hem de terapistler tarafindan psikoterapide anahtar bir faktör olarak sürekli değerlendirilmesi gereken umudun, insan adaptasyonunun ve psikoterapötik değişimin merkezinde olmasıdır. ${ }^{23}$

Lysaker ve ark. $^{24}$ (2005) yaptıkları çalışmada, şizofreni hastalarının umut ve içgörü düzeyleri arasında önemli bir ilişki olduğunu, ayrıca umut ve içgörünün yüksekliğinin hastalığa adaptasyonu kolaylaştırdığını ortaya koymuşlardır. Lysaker ve Salyers ${ }^{25}$ (2007) şizofreni hastalarında yüksek anksiyetenin yüksek umutsuzluk seviyesi ile ilişkili olduğunu saptamıştır. Salerno ${ }^{26}$ (2002) 107 şizofreni hastasıyla yürüttüğü çalışmada, yüksek umut seviyesinin hastalıkla baş etme gücü ve olumlu kendilik algısını artırdığını bildirmiştir. Hofer ve ark.'nın ${ }^{27}$ (2016) Japonya ve Avusturya'da yaşayan şizofreni hastalarıyla yaptıkları bir kültürel karşılaştırma çalışmasında, her iki kültürde de yüksek umudun, hastaların en önemli sorunlarından birisi olan içselleştirilmiş damgalanma seviyelerini azalttığ Lyu ve Zhang ${ }^{28}$ (2014) ise yaptıkları çalışmada, umut düzeyi düşük olan şizofreni hastalarının, daha fazla intihara teşebbüs ettiklerini belirtmişlerdir. Vrbova ve ark. ${ }^{29}$ (2017) şizofreni hastalarıyla yaptıkları bir kesitsel araştırma 
çalışmasında, umudun hastaların yaşam kalitesinin belirleyicilerinden birisi olduğunu ortaya koymuşlardır.

Literatür incelendiğinde ülkemizde de şizofreni hastalığında umut konusunun ele alındığı çeşitli araştırmalara rastlanmıştır. Yıldırım $^{30}$ (2009) 180 şizofreni hastasiyla yürüttüğü çalışmasında, hastaların umut düzeyleri arttıkça yaşam kalitelerinin de arttığını bildirmiştir. Coşkun ve Şahin Altun ${ }^{31}$ (2017)'un çalışmasında, şizofreni hastalarının umut düzeylerinin, fonksiyonel iyileşme düzeyleri üzerinde belirleyici olduğu belirtilmiştir. Öztürk ${ }^{32}$ (2012) intihar girişimi olan şizofreni hastalarının, umutsuzluk düzeylerinin yüksek olduğunu saptamıştır. Değer ${ }^{33}$ (2012) travma öyküsü bulunan şizofreni hastalarının umutsuzluk ile intihar düşüncelerinin yüksek olduğunu ortaya koymuştur. Olçun ve Şahin Altun $^{34}$ (2017)'un yaptığ 1 çalışmada ise, şizofreni hastalarında yüksek umudun, içselleştirilmiş damgalanma düzeyini azalttığı, damgalanmaya karşı direnci ise artırdığı bulunmuştur.

Umut gelişimi destekleyen ve hastalıklarla başa çıkmayı sağlayan önemli bir unsur olmasına rağmen, mental sağlık problemleri olan kişilerde diğer hastalıklara kıyasla daha az dikkat edilen bir kavramdır. ${ }^{35,36}$ Barut ve ark. ${ }^{37}$ (2016) şizofreni gibi ruhsal hastalıklarda umudun rolünü inceleyen araştırmaların literatürde yeterli düzeyde olmadığını belirtmiştir. Şizofreni hastalığında umudu ele alan sınırlı sayıda çalışmada ise, genellikle deneysel olmayan araştırma tasarımlarının kullanıldığ çalışmalara gereksinim olduğu bildirilmektedir. ${ }^{12,35-37}$ Uluslararası çalışmalar incelendiğinde, özellikle hemşirelik biliminde yürütülen umut konulu çalışmaların, çoğunlukla kanser hastalarına odaklandığı görülmektedir. ${ }^{38,39}$ Ülkemizde de umut genellikle kanser hastalı̆̆ıyla beraber ele alınmıştır. ${ }^{40-42} \mathrm{Bu}$ nedenle psikiyatrik rehabilitasyonda umudu ve artırma yöntemlerini ele alan özellikle randomize kontrollü çalışmalara gereksinim vardır. ${ }^{12}$

\section{Umudu artırma stratejileri ve hemşirelik girişimleri}

Umut kavramına yönelik sağlık ekibinin farkındalığının artırılması, hastada destekleyici bir iç güç olan umudun harekete geçirilmesini sağlayarak, zorlu durumlar karşısında baş etme stratejilerini artıracaktır. ${ }^{43,44}$ NANDA tarafindan 1986'da bir hemşirelik tanısı olarak kabul edilen umutsuzluk; bireyin sınırlı ya da hiç alternatif görmediği, kişisel seçenekler bulamadığ 1 ve kendi yararı için enerji sarf edemediği bir durum olarak tanımlanmaktadır. ${ }^{14}$ Şizofreni hastalığının tanı, tedavi ve rehabilitasyon aşamalarında en fazla hastaların yanlarında bulunan sağl1k profesyoneli olan hemşirelerin, umudu tanımlamaları, artırmaya yönelik faktörleri ve stratejileri bilmeleri şizofreni tedavisinde büyük önem taşımaktadır. ${ }^{12,14}$

Umudu artırma stratejilerinin tartışlabilmesi için hastaların umutlu olmalarının önündeki iç ve dış engellerin hemşireler tarafından iyi değerlendirilmesi gereklidir.

> İçsel engeller, hastanın kişisel özellikleri ve hastalığa bağlı sorunlar nedeniyle ortaya çıkar. Bu engeller: hastalığın kronik olması, zorlu tedavi süreci, nükslerle devam etmesi, işlevsellikte azalma, yeti yitimleri, kişiler arası ilişkileri sürdürmedeki güçlükler ve baş etme sorunları olarak sıralanabilir.

$>$ Dişsal engeller, hasta bireye toplum ve sağl1k profesyonellerince uygulanan olumsuz yaklaşımlardan oluşur. $\mathrm{Bu}$ engeller: toplum ve sağlık çalışanlarının hastalara karşı sergiledikleri ayrımcı, dışlayıcı ve damgalayıcı davranışlardan oluşmaktadır. Hastaların dinlenilmemesi, nazik ve saygıll bir şekilde davranılmamas1, mevzuat tarafindan kendilerine sunulan haklardan mahrum bırakılmaları umudu azaltıcı dışsal faktörlerdir. ${ }^{45}$

Umut güçlendirmeye yönelik, hemşirelerin dikkat etmesi gereken faktörler 3 başlık altında incelenmektedir.

1. Hemşirelerin şizofreni hastalariyla iletişim kurarken dikkat etmesi gereken faktörler; orada olmak, cesaretlendirmek, desteklemek, nazik davranmak ve dürüst olmaktır.

2. Hemşirelerin hastaların günlük hayatta başarılı olmalar için onları desteklemesi gereken faktörler; gerçekçi hedefler belirleme, günlük görevleri yerine getirme, kendisiyle ilgili yaptığı olumsuz tanımlamaları değiştirme ve çalışma yaşamındaki hedeflere ulaşması konusunda yardımcı olmaktır.

3. Hemşirelerin hastalığın yönetimi ve kontrol altına alınmasi konusunda özen göstermeleri gereken faktörler; tedaviye uyum, holistik bakım, semptom kontrolü ve alevlenmelerin öncü belirtilerini tanımaktır. ${ }^{12}$

Umut aş1lamaya yönelik hemşirelerin uygulayabileceği girişimler ise beş başlık altında toplanmaktadır. Bunlar:

> İlişkileri geliştirmek 
Başarıyı kolaylaştırmak

Başarılı rol modellerle bağlantı kurmak

Hastalığ yönetmek

Toplumu ve hastaları eğitmektir.

İlişkileri geliştirmek: Umudun artırılmasinda sağlık profesyonelleri ve hastalar arasında kurulan ilişki önemli bir etkiye sahiptir. Hemşirelerin hastalara zaman ayırmaları, onları dinlemeleri ve sorularına açıklayıcı cevaplar vermeleri hastalara değer verildiğini göstermesi açısından önemlidir. Hastayla kurulan terapötik ilișkinin geliștirilmesi, onun bir birey olarak kabul edilmesi ve bakış açısını anlamak için gereklidir. Hemşirelerin hastalarla kuracakları sağlıklı ve güven ilişkilerine dayanan terapötik bir iletişim hastaların umutlarının artmasını sağlamaktadır. ${ }^{42,45}$

Başarıyı kolaylaştırmak: Başarı deneyimine sahip olmak umudu artırıcı bir strateji olarak görev yapmaktadır. Hedefler belirleme, bu hedefe götürecek yolları seçme ve hedeflere ulaşmak bu girișimin önemli bir bileşenidir. Hastalar kendilerini başarılı hissettiklerinde, kendi yaşamlarına yönelik kontrolleri artmakta ve benlik saygıları yükselmektedir. Bu nedenle hemşireler amaçlar belirleme ve bunlara ulaşmak konusunda hastaları desteklemelidir. ${ }^{45}$

Rol modellerle bağlantı kurmak: $\mathrm{Bu}$ strateji hastaları şizofreni ile mücadelede başarılı olan başka bir hastayla bir araya getirmeyi içerir. Hastalar kendileriyle benzer durumları deneyimleyen farklı bireylerle karşılaşınca, yaşadıkları sorunların sadece kendilerine özgü olmadığını anlarlar ve yalnız olmadıklarını hissederler.

Hastalığl yönetmek: Şizofreni hastalarının ilaçlarını düzenli kullanmaları, kontrollerini aksatmamaları, hastalığın alevlenme dönemlerinin öncü belirtilerini bilmeleri, baş etme becerilerini öğrenmeleri ve uygulamaları hastalığın yol açtığ olumsuzlukları azalttığından, umudu geliştirir. Hastalığı yönetemeyen şizofreni hastaları arasında depresyon ve umutsuzluk sik karşılaşılan sorunlardır. Hemşireler hastalığı yönetme konusunda hastalara yardımcı olmalıdır. ${ }^{45}$

Toplumu ve hastaları eğitmek: Şizofreni hastalığ 1 konusunda hastaları ve toplumu eğitmek hemşirelerin görevidir. Hemşireler hastalık süreci, özellikleri, yol açtığı sorunlar ve baş etme stratejileri konusunda hastaları eğitmelidirler. Topluma ruhsal hastalıklarla ilgili bilginin geliştirilmesi ve hastalara yönelik negatif tutumların azaltılmasına yönelik yapılandırılmış eğitimler verilmesi hemşirelerin sorumluluğudur. Hemşireler bu amaçla okul ve işyeri gibi toplu alanlarda eğitim vererek toplumsal değişime katkı sağlayabilirler. ${ }^{42,45}$

Hemşireler, umut aş1lamaya yönelik bu girişimleriyle şizofreni hastalarının yaşamlarında pozitif değişiklikler oluşmasında ve geleceklerine dair olumlu beklentiler geliştirmelerinde önemli bir rolü üstlenmektedir. ${ }^{12,14}$

\section{Sonuc}

Umut mental hastalığ 1 olan bireylerin, hastalıklarının üstesinden gelmelerine ve hayatın anlamını keşfetmelerine yardım eder. Yapılan araştırmalar da şizofreni hastalığının tedavisinde umudun önemli bir bileşen olduğu vurgulanmasına rağmen, literatürde bu konunun ele alındığı çalışmalar oldukça sinırlıdır. Özellikle hemşirelik biliminde yürütülen umut konulu çalışmalar, çoğunlukla kanser hastalarına odaklanmıştır. $\mathrm{Bu}$ nedenle özellikle hemşirelik bağlamında umudu ve artırma yöntemlerini ele alan çalışmalara gereksinim vardır. Şizofreni hastalığının tanı, tedavi ve rehabilitasyon aşamalarında en fazla hastaların yanlarında bulunan sağlik profesyoneli olan hemşirelerin, umudu tanımlamaları ve artırmaya yönelik uygun girişimlerde bulunmaları, şizofreni tedavisinde fark yaratabilir.

\section{Kaynaklar}

1. Aghevli MA, Blanchard JJ, Horan WP. The expression and experience of emotion in schizophrenia: a study of social interactions. Psychiatry Res. 2003;119(3):261-270.

2. Öztürk O, Uluşahin N. Ruh Sağlı̆ğ ve Bozuklukları. 13. Baskı. Ankara: Nobel Tip Kitapevi; 2015. p.189-261.

3. Yüksel N. Ruhsal Hastalıklar, 4. Baskı. Ankara: Akademisyen Tip Kitapevi; 2014. p.325-375.

4. Lysaker PH, Clements CA, Wright DE, Evans J, Marks KA. Neurocognitive correlates of helplessness, hopelessness, and well-being in schizophrenia. The Journal of Nervous and Mental Disease. 2001;189(7):457-462.

5. Brohan E, Elgie R, Sartorius N, Thornicroft G, GAMIAN-Europe Study Group. Selfstigma, empowerment and perceived discrimination among people with schizophrenia in 14 European countries. Schizophrenia Research. 2010;122(1):232238.

6. Noh C, Choe K, Yang B. Hope from the perspective of people with schizophrenia 
(Korea). Archives of Psychiatric Nursing. 2008;22(2):69-77.

7. Lysaker PH, Vohs JL, Tsai J. Negative symptoms and concordant impairments in attention in schizophrenia: associations with social functioning, hope, self-esteem and internalized stigma. Schizophrenia Research. 2009;110(1):165-172.

8. Mashiach-Eizenberg M, Hasson-Ohayon I, Yanos, PT, Lysaker PH, Roe D. Internalized stigma and quality of life among persons with severe mental illness: the mediating roles of self-esteem and hope. Psychiatry Research. 2013;208(1):15-20.

9. Fitzgerald R. The sources of hope. New York: Pergamon; 1979. p.224-254.

10. Corrigan PW, McCracken SG, Holmes EP. Motivational interviews as goal assessment for persons with psychiatric disability. Community Mental Health Journal. 2001;37(2): 113-122.

11. White RG, McCleery M, Gumley AI, Mulholland C. Hopelessness in schizophrenia: the impact of symptoms and beliefs about illness. The Journal of Nervous and Mental Disease. 2007;195(12):968-975.

12. Kylma J, Juvakka T, Nikkonen M, Korhonen T, Isohanni M. Hope and schizophrenia: an integrative review. Journal of Psychiatric and Mental Health Nursing. 2006;13:651-664.

13. Moore SL. Hope makes a difference. Journal of Psychiatric and Mental Health Nursing. 2005;12(1):100-105.

14. Öz F. Sağlık Alanında Temel Kavramlar, 2. Baskı. Ankara: Mattek Matbaacıllk Basımevi; 2010. p.189-224.

15. Schrank B, Hayward M, Stanghellini G, Davidson L. Hope in psychiatry. Advances in Psychiatric Treatment. 2011;17(3):227-235.

16. Snyder CR, Crowson JJ. Hope and coping with cancer by collage women. J Pers. 1998;66(2):195-214.

17.Akman Y, Korkut F. Umut ölçeği üzerine bir araştırma. Eğitim Fakültesi Dergisi. 1993;9(2):193-203.

18. Landeen J, Pawlick J, Woodside H, Kirkpatrick H, Byrne C. Hope, quality of life, and symptom severity in individuals with schizophrenia. Psychiatric Rehabilitation Journal. 2000;23(4):364-369.

19. Miller J, Powers M. Development of an instrument to measure hope. Nursing Research. 1988;37:6-10.
20. Menninger K. The academic lecture: Hope. American Journal of Psychiatry, 1959;116(6):481-491.

21.Gelling L, Fitzgerald MA, Blight I. Hope in the ICU: A qualitative study exploring nurses' experiences of the concept of hope. Nursing in Critical Care. 2002;7(6):271-277.

22.Heszen-Niejodek I, Gottschalk LA, Januszek M. Anxiety and hope during the course of three different medical illnesses: A longitudinal study. Psychotherapy and Psychosomatics. 1999;68(6):304-312.

23. Schrank B, Stanghellini G, Slade M. Hope in psychiatry: a review of the literature. Acta Psychiatrica Scandinavica. 2008;118(6):421433.

24.Lysaker PH, Campbell K, Johannesen JK. Hope, awareness of illness, and coping in schizophrenia spectrum disorders. Journal of Nervous and Mental Disease. 2005;193(5):287-292.

25.Lysaker PH, Salyers MP. Anxiety symptoms in schizophrenia spectrum disorders: associations with social function, positive and negative symptoms, hope and trauma history. Acta Psychiatrica Scandinavica. 2007;116(4):290-298.

26. Salerno EM. Hope, power and perception of self in individuals recovering from schizophrenia: a Rogerian perspective. Visions: The Journal of Rogerian Nursing Science. 2002;10(1):2336.

27.Hofer A, Mizuno Y, Frajo-Apor B, Kemmler G, Suzuki T, Pardeller S, et al. Resilience, internalized stigma, self-esteem, and hopelessness among people with schizophrenia: Cultural comparison in Austria and Japan. Schizophrenia Research. 2016;171(1):86-91.

28. Lyu J, Zhang J. Characteristics of schizophrenia suicides compared with suicides by other diagnosed psychiatric disorders and those without a psychiatric disorder. Schizophrenia Research. 2014;155(1):59-65.

29. Vrbova K, Prasko J, Ociskova M, Kamaradova D, Marackova M, Holubova M, et al. Quality of life, self-stigma, and hope in schizophrenia spectrum disorders: a crosssectional study. Neuropsychiatric disease and treatment. 2017;13(1):567-575.

30. Yıldırım DL. Şizofren hastaların umut düzeyinin yaşam kalitesine etkisi. Marmara Üniversitesi, Sağlık Bilimleri Enstitüsü, 
Psikiyatri Hemşireliği Anabilim Dal, Yüksek Lisans Tezi, İstanbul, 2009.

31.Coşkun E, Altun ÖŞ. The Relationship between the hope levels of patients with schizophrenia and functional recovery. Archives of psychiatric nursing. 2017, Baskıda.

32. Öztürk HM. Şizofreni hastalarında intihar girişiminin pozitif ve negatif semptomlar, depresyon, umutsuzluk, içgörü ve bilişsel işlevlerle ilişkisi. Gazi Üniversitesi, Tıp Fakültesi, Psikiyatri Anabilim Dalı, Uzmanlık Tezi, Ankara, 2012.

33.Değer ÖD. Şizofrenide travma öyküsünün anksiyete semptomları, umutsuzluk ve intihar düşüncesi ile ilişkisi. Bakırköy Prof. Dr. Mazhar

Osman

Ruh Sağlığı ve Sinir Hastalıkları Eğitim ve Araştırma Hastanesi, Psikiyatri Kliniği, Psikiyatri Uzmanlık Tezi, İstanbul, 2012.

34. Olçun Z. Altun ÖȘ. The correlation between schizophrenic patients' level of internalized stigma and their level of hope. Archives of psychiatric nursing. 2017;31(4):332-337.

35. Vaillot MC. Living and dying. Hope: the restoration of being. The American Journal of Nursing. 1970;70(2):268-273.

36. Korner IN. Hope as a method of coping. Journal of Consulting and Clinical Psychology. 1970;34(2):134-139.

37.Barut JK, Dietrich MS, Zanoni PA, Ridner $\mathrm{SH}$. Sense of belonging and hope in the lives of persons with schizophrenia. Archives of Psychiatric Nursing. 2016;30(2):178-184.

38.Lee EH. Fatigue and hope: relationships to psychosocial adjustment in Korean women with breast cancer. Applied Nursing Research. 2001;14(2):87-93.

39.Lai YH, Chang JTC, Keefe FJ, Chiou CF, Chen SC, Feng SC, et al. Symptom distress, catastrophic thinking, and hope in nasopharyngeal carcinoma patients. Cancer Nursing, 2003;26(6):485-493.

40.Kelleci M. Kanser hastalarının umudunun geliştirilmesine yönelik hemşirelik girişimleri. Anadolu Psikiyatri Dergisi. 2005;6(1):41-47.

41.Kavradım ST, Özer ZC. Kanser tanısı alan hastalarda umut. Psikiyatride Güncel Yaklaşımlar. 2014;6(2):154-164.

42. Aslan Ö, Sekmen K, Kömürcü Ş, Özet A. Kanserli hastalarda umut. Cumhuriyet Üniversitesi Hemşirelik Yüksekokulu Dergisi. 2007;11(2):18-24.
43.Duggleby W. Hope at the end of life. J Hosp Palliat Nurs. 2001;3(2):51-64.

44. Cutcliffe J, Herth, K. The concept of hope in nursing 2: hope and mental health nursing. British Journal of Nursing. 2002;11(13):885-893.

45. Kirkpatrick H, Landeen J, Byrne C, Woodside H, Pawlick J, Bernardo A. Hope and schizophrenia: clinicians identify hopeinstilling strategies. Journal of Psychosocial Nursing and Mental Health Services. 1995;33(6):15-19. 